\title{
Manajemen Asuhan Kebidanan Bayi Baru Lahir pada Bayi Ny "A" dengan Hipotermi di RSUD Syekh Yusuf Gowa Tanggal 12 Oktober-01 Desember 2018
}

\author{
${ }^{1}$ Miranti Arti, ${ }^{2}$ Anieq Mumthi'ah Al Kautzar, ${ }^{3}$ Zelna
}

\begin{abstract}
ABSTRAK
Pendahuluan Hipotermi adalah bayi dengan suhu badan di bawah normal. Adapun suhu normal bayi $36,5-37,5^{\circ} \mathrm{C}$. Suhu bayi yang rendah mengakibatkan proses metabolik dan fisiologi melambat. Kecepatan pernafasan dan denyut jantung bayi melambat, tekanan darah rendah dan kesadaran menghilang. Bila keadaan ini berlanjut dan tidak segera mendapatkan penanganan maka dapat menimbulkan kematian pada bayi. Karya tulis ini bertujuan untuk melaksanakan Manajemen Asuhan Kebidanan Bayi Baru Lahir dengan Hipotermi di RSUD Syekh Yusuf Gowa Tahun 2018 sesuai dengan 7 Langkah Varney dan SOAP. Pemantauan studi kasus pada bayi Ny "H" dilakukan sebanyak 6 kali selama kurang lebih 1 bulan.
\end{abstract}

Hasil HPHT tanggal 20 januari 2018 , HTP 27 oktober 2018 dan melahirkan tanggal 15 Oktober 2018 pukul 12.30 wita, usia kehamilannya yaitu 38 minggu 2 hari, ibu sering datang memeriksakan kehamilannya dipelayanan kesehatan dan ibu juga telah mendapatkan suntik TT, ibu mengatakan tidak ada riwayat penyakit serius. Bayi lahir normal, presentase belakang kepala dengan berat badan 2500 gram, panjang badannya yaitu $47 \mathrm{~cm}$, keadaan umum bayi baik, bayi lahir tanggal 15 Oktober 2018 pukul 12:30 wita dengan Apgar Score 8/10.

Kesimpulan dari studi kasus bayi Ny "A" dengan Hipotermi di RSUD Syekh Yusuf Gowa Tahun 2018 dengan menggunakan 7 Langkah Varney dan SOAP untuk proses penyelesaian masalah kebidanan, telah dilaksanakan pengkajian dan analisa data terhadap bayi Ny "A" dengan hasil tidak terjadi Hipotermi dan tidak ditemukannya kesenjangan antara teori dan kasus nyata yang ada di lapangan.
*UIN Alauddin Makassar

*mirantiarti7@gmail.com
Kata kunci :

Bayi Baru Lahir;

Hipotermi;

7 Langkah Varney

\section{PENDAHULUAN}

Hipotermi merupakan keadaan di mana seseorang individu mengalami penurunan suhu tibuh terus menerus di bawah $35,5^{\circ} \mathrm{C}$. Suhu bayi yang rendah mengakibatkan proses metabolik dan fisiologi melambat. Kecepatan pernafasan dan denyut jantung bayi melambat, tekanan darah rendah dan kesadaran menghilang.Bila keadaan ini berlanjut dan tidak segera mendapatkan penanganan maka dapat menimbulkan kematian pada bayi (hutagaol dkk, 2014). 
World Health Organization (WHO) telah merekomendasikan asuhan untuk mempertahankan panas dalam asuhan bayi baru lahir, namun hipotermia terus berlanjut menjadi kondisi biasa terjadi pada neonatal, yang tidak diketahui, tidak dokumentasikan dan kurang memperoleh penanganan, prevalensi yang tinggi dari hipotermi telah dilaporkan secara luas bahkan di negara tropis (Hotma dan Eryati,2014).

Berdasarkan data yang diproleh dan pencatatan dan pelaporan RSUD Syekh Yusuf Gowa pada tahun 2014 sebanyak 11 bayi , pada tahun 2015 sebanyak 37 bayi, pada tahun 2016 sebanyak 23 bayi dan sampai pada tahun 2017 jumlah keseluruhan sebanyak 13 bayi mengalami hipotermi.(rekan medik rumah sakit Syekh Yusuf Gowa).

Angka kematian bayi tergolong masih cukup tinggi yaitu per 1.000 kelahiran hidup. Angka kematian bayi (infant mortality rate) di negara-negara maju telah turun dengan cepat dan sekarang mencapai angka dibawah 20 per 1.000 kelahiran hidup. bayi baru lahir kehilangan panas empat kali lebih besar dari pada orang dewasa, sehingga mengakibatkan terjadinya penurunan suhu. Pada 30 menit pertama bayi dapat mengalami penurunan suhu 3 $4^{\circ} \mathrm{C}$ pada penurunan dengan suhu $20-25^{\circ} \mathrm{C}$ suhu kulit bayi turun sekitar $0,3^{\circ} \mathrm{C}$ permenit. penurunan suhu diakibatkan oleh kehilangan panas secara konduksi,konvensi,evaporasidan radiasi. kemampuan bayi yang belum sempurna dalam memproduksi panas maka bayi sangat rentan untuk mengalami hipotermi(Hotma dan Eryati 2014). Angka kematian neonatal di kota Makassar mengalami fluktuasi dari tahun ke tahun. Pada tahun 2015 sebesar 1,19 per 1.000 kelahiran hidup (AKN:1,19/1.000 kelahiran hidup) meningkat dari tahun 2014 sebesar 0,98 per 1.000 kelahiran hidup (AKN:0,98/1000 kelahiran hidup ).Tahun 2013 sebesar 2,44 per 1.000 kelahiran (AKN:2.44/1.000 kelahiram hidup) (Profil Kesehatan Kota Makassar,2015).

Di Sulawesi Selatan, Angka Kematian Bayi menunjukkan angka penurunan yang sangat tajam, yaitu dari 161 per 1.000 kelahiran hidup pada tahun 1971 menjadi 55 pada tahun 1996, lalu turun lahir menjadi 52 pada tahun 1998 kemudian pada tahun 2003 menjadi 48 (Susenas 2003). Ini berarti rata-rata penurunan AKB selama kurun waktu 1998-2003 sekitar 4 poin. Namun menurut hasil Surkenas/ Susenas 2002-2003, AKB di Sulawesi Selatan sebesar 47 per 1.000 kelahiran hidup, dan hasil SDKI 2007 menunjukkan angka 41 per 1.000 kelahiran hidup. Dari hasil pengumpulan data Profil Kesehatan tahun 2016 jumlah kematian bayi menjadi 1.179 bayi atau 7,49 per 1.000 kelahiran hidup maka masih perlu peran dari semua pihak yang terkait dalam rangka penurunan angka tersebut sehingga target Sustainable 
Development Goals (SDGs)khususnya penurunan angka kematian dapat tercapai (Profil Dinas Kesehatan Profinsi Sulawesi Selatan tahun 2017).

\section{METODE PENELITIAN}

Melaksanakan studi kasus dengan pendekatan Manajemen Asuhan Kebidanan sesuai dengan 7 langkahVarney dan pendokumentasian dalam bentuk SOAP. Penatalaksanaan Asuhan dilakukan dengan pemberian asuhan yang sesuai standar operasional prosedur pada kasus yang diteliti yaitu Manajemen Asuhan Kebidanan pada Bayi Baru Lahir dengan Hipotermi .

\section{HASIL PENELITIAN}

Penelitian ini dilakukan di RSUD Syekh Yusuf Gowa tepat dengan pembahasan tentang asuhan kebidanan bayi baru lahir pada bayi Ny"A" dengan hipotermi pada tanggal 12 oktober -01 desember tahun 2018. Pembahasan ini dibuat berdasarkan landasan teoritis dan studi kasus yang dapat dianalisa secara teoritis untuk memudahkan memahami kesenjangan dan kesesuaian yang terjadi pada kasus ini dengan berdasarkan pada pendekatan asuhan kebidanan dengan tujuh langkah varney yakni: pengumpulan data dasar, merumuskan diagnosis atau masalah potensial, melaksanakan tindakan segera atau kolaborasi, merencanakan tindakan asuhan kebidanan.

Pengkajian dan analisa data yang diberikan dengan asuhan kebidanan sangat penting dilakukan karena merupakan langkah awal yang kiranya perlu penanganan cermat sehingga masalah - masalah dapat terdeteksi secara dini dan tidak tidak berlanjut kemasalah kematian. Dari data subjektif yang didapatkan Bayi Ny "A" dengan usia kehamilan 38 minggu 2 hari dengan berat badan lahir 2500 gram lahir secara spontan, maka ditegakkan diagnosa/masalah aktual BCB/SMK/lahir normal.

Diagnosa/masalah potensil yang ditegakkan pada Bayi Ny "A" dengan hipotermi yaitu rentan terjadi hipoglikemia .Tindakan segera/kolaborasi pada Bayi Ny "A" tidak ada data yang mendukung perlunya tindakan segera.

\section{PEMBAHASAN}

Rencana asuhan kebidanan pada Bayi Ny "A" dengan hipotermi direncanakan seluruh kegiatan yang akan dilakukan untuk menangani bayi dengan hipotermi serta komplikasi- 
Berdasarkan data yang diambil dari studi kasus bayi Ny "A" umur 0 hari hipotermi selama bayi dirawat di Rumah Sakit sampai dilakukan kunjungan rumah klien meliputi :

HPHT tanggal 20-01-2018, taksiran persalinan tanggal 27-10-2018, anak pertama dan tidak pernah mengalami keguguran, malakukan pemeriksaan kehamilan sebanyak 2 kali, mendapatkan suntikan TT 2 kali, selama hamil ibu jarang mengkonsumsi tablet Fe, Tidak pernah menderita riwayat penyakit yang serius. Bayi lahir secara spontan, presentase balakang kepala, umur kehamilan 38 minggu 2 hari, dengan berat badan 2500 gram, jenis kelamin perempuan lahir pada tanggal 15 oktober, pukul 12:30 wita.

Umur 0 hari dirawat di infant warmer, keadaan umum bayi normal, berat badan 2500 gram, panjang badan $47 \mathrm{~cm}$, refleks menghisap dan menelan baik dan dapat menghisap puting susu ibu, tanda-tanda vital : Denyut jantung $124 \mathrm{x} / \mathrm{i}$, pernafasan $44 \mathrm{x} / \mathrm{i}$, suhu $35,5^{\circ} \mathrm{C}$, gerakan dada sesuai dengan gerakan nafas, keadaan tali pusat masih basah, keadaan tali pusat masih basah, tidak ada kelainan pada genitalia, gerakan tangan dan kaki baik, lemak kulit kurang, tampak kemerahan dan lanugo sedikit dan bayi diberi ASI Eksklusif oleh ibunya.

Umur 2 hari bayi masih di bedong, keadaan umum bayi baik, berat badan 2500 gram, refleks menghisap sedang, tanda-tanda vital : denyut jantung $138 \mathrm{x} / \mathrm{i}$, pernafasan $54 \mathrm{x} / \mathrm{i}$, suhu $36,5^{\circ} \mathrm{C}$, gerakan dada sesuai dengan pola nafas, lemak kulit kurang, tampak kemerahan, lanugo sedikit, tali pusat masih basah tampak bersih, tidak ada infeksi, bayi diberi ASI eksklusif oleh ibunya dan refleks mengisap dan menelan baik.

Umur 7 hari bayi keadaan umum bayi baik, bayi menyusui dengan teratur dan sudah bisa menghisap puting susu ibunya, berat badan 2700 gram, tanda-tanda vital : denyut jatung 140x/i, pernafasan $52 x /$ i, suhu $36,6^{\circ} \mathrm{C}$, kulit tampka kemerahan, dan sedikit lemak, gerakan dada sesuai dengan pola nafas, bayi diberi ASI eksklusif oleh ibunya.

Kunjungan pertama umur empat belas hari bayi sudah dirawat dirumah, keadaan umum bayi baik, bayi menghisap dengan kuat dan menelan dengan baik, bayi banyak tidur, tanda-tanda vital : denyut jantung $140 \mathrm{x} / \mathrm{i}$, pernafasan $58 \mathrm{x} / \mathrm{i}$, suhu $36,8^{\circ} \mathrm{C}$, berat badan 2700 gram panjang badan $\mathrm{cm}$, gerakan dada sesuai dengan pola nafas, tali pusat sudah puput, tampak bersih, tidak ada infeksi, refleks menghisap dan menelan sudah baik.

Kunjungan kedua umur bayi dua puluh satu hari, keadaan umum bayi baik, bayi menghisap dengan kuat dan menelan dengan baik, bayi banyak tidur, bayi selalu diberi ASI eksklusif oleh ibunya, berta badan 2700 gram, tanda-tanda vital : denyut jantung 140x/i, 
pernafasan $58 \mathrm{x} / \mathrm{i}$, suhu $36,6^{\circ} \mathrm{C}$, refleks menelan dan menghisap baik, tali pusat sudah puput, tampak bersih, tidak ada infeksi, bayi diberi ASI dengan ASI eksklusif oleh ibunya.

Kunjungan ketiga umur bayi 28 hari, keadaan bayi baik, bayi banyak tidur, berat badan bayi sudah diatas 2800 gram . Bayi selalu diberi ASI eksklusif, tali pusat sudah puput, tampak bersih, tidak ada infeksi, konjungtiva tampak merah muda, tanda-tanda vital : denyut jantung $140 \mathrm{x} / \mathrm{i}$, pernafasan $58 \mathrm{x} / \mathrm{i}$, suhu $36,7^{\circ} \mathrm{C}$, kulit tampak kemerahan, gerakan dada sesuai dengan pola nafas, refleks menghisap dan menelan baik.

Berdasarkan tinjauan teori etiologi yang mempengaruhi terjadinya hipotermi yaitu faktor ibu : jarak hamil dan bersalin terlalu dekat, kebiasaan ibu ketergantungan obat narkotika, merokok dan minum alkohol, ibu bekerja terlalu berat (Julina Br. 2017:163).

Hipotermi merupakan keadaan di mana seseorang individu mengalami penurunan suhu tibuh terus menerus di bawah $35,5^{\circ} \mathrm{C}$. Suhu bayi yang rendah mengakibatkan proses metabolik dan fisiologi melambat.

Berdasarkan tinjauan teoritis dan studi kasus pada bayi Ny "A" dengan Hipotermi ditemukan banyak persamaan dengan tinjauan toritis dan studi kasus sehingga terjadi perbedaan yang menyebabkan bayi Ny “A” dengan Bayi Hipotermi.

\section{KESIMPULAN DAN SARAN}

\section{A. KESIMPULAN}

1. Telah dilaksanakan pengkajian dan analisa data bayi baru lahir pada Ny"A" dengan hipotermi sedang di Rumah Sakit Umum Daerah Syekh Yusuf Gowa tahun 2018.

2. Telah dilaksankan perumusan diagnosa / masalah aktual bayi baru lahir pada Ny"A" dengan hipotermi sedang di Rumah Sakit Umum Daerah Syekh Yusuf Gowa tahun 2018.

3. Telah dilaksanakan perumusan diagnosa / masalah pontesial bayi baru lahir dengan hipotermi sedang di Rumah Sakit Umum Daerah Syekh Yusuf Gowa tahun 2018.

4. Telah megindentifikasi perlunya tindakan segera dan kaloborasi bayi baru lahir pada Ny"A" dengan hipotermi sedang di Rumah Sakit Umum Daerah Syekh Yusuf Gowa tahun 2018.

5. Telah menetapkan rencana tindakan asuhan kebidanan bayi baru lahir pada Ny"A" dengan hipotermi sedang di Rumah Sakit Umum Daerah Syekh Yusuf Gowa tahun 2018. 
6. Melaksanakan tindakan asuhan kebidanan yang telah disusun pada bayi Ny"A" dengan hipotermi sedang di Rumah Sakit Umum Daerah Syekh Yusuf Gowa dengan hasil yaitu semua tindakan yang telah direncanakan dapat dilaksanakan seluruhnya dengan baik tanpa adanya hambatan.

\section{B. SARAN}

Adapun saran yang penulis kemukakan untuk mencapai asuhan kebidanan yang baik, diperlukan :

\section{Bagi ibu bayi}

a. Diharapkan pada setiap ibu yang memiliki bayi baru lahir agar senantiasa menjaga kehangatan suhu tubuh bayi untuk mencegah terjadinya syok akibat hipotermi.

b. Diharapkan kepada ibu bayi agar memberiakn ASI secara ekslusif, merawat tali pusat, menganti popok / celana jika lembab atau basah, mempertahankan menjaga suhu tubuh bayi dengan membungkus dengan kain / sarung kering dan bersih, observasi eliminasi bayi.

c. Diperlukan keterlibatan dari suami / keluarga dalam perawatan untuk meningkatan hubungan yang lebih erat antara ibu dan bayinya demii menambah pengetahuan dan bimbinngan sebagai kelanjutan perawatan.

\section{Untuk bidan}

a. Bidan sebagai tenaga kesehatan sangat berperan dalam menurunkan angka kematian bayi dengan memberikan perawatan untuk mencegah terjadinya komplikasi.

b. Sebagai bidan diharapkan senantiasa berupaya meningkatkan pengetahuan dan keterampilan dalam melaksanakan pelayanan sebagai pertanggung jawaban apabila ada gugutan.

c. Kerja sama dan komunikasi yang baik antara petugas professional lain ( dokter, perawat, dan sesama bidan) agar proses berjalan dengan mudah. 
d. Sebagai tenaga bidan yang profesional dan muslima harus dapat memberikan dukungan, motivasi agar ibu senantiasa merawat bayinya dengan baik. Perlunya bukti pertanggung jawaban petugas kesehatan terhadap semua asuhan yang diberikan maka setiap tindakan yang dilakukan harus didokumentasikan.

\section{DAFTAR PUSTAKA}

Asri, D. Cristine, C. Asuhan Persalinan Nomal. Prinsip Asuhan Bayi Baru Lahir Normal. MuhamedikaYogjakarta, 2012.

ChaidirReny. Jurnal. Pengaruh Inisiasi Menyusui Dini Terhadap Suhu Tubuh Bayi Baru Lahir di BPM PdangPanjang: STIKES Yarsi Sumbar Bukit tinggi, Vol 11.il No 20, 2016.

Erna dan Sugiarti. Kegawat Daruratan Maternitas Pada Ibu Hamil, Bersalin, Nifas. Indomedika Pustaka, 2017.

Fidadanmaya. Pengantar Ilmu Kesehatan Anak. D-Medika, 2012.

Hendrawati, S. et al. Kebutuhan Orang Tua dalam Perawatan Bayi Sakit Kritis di Neonatal Intensive Care Unit (NICU), 2018.

Ilmiah, Shofa Widia. Asuhan Persalinan Normal. Nuha Medika.Yogyakarta,2015

Indriyani,Moudy Emma Unaria D. Asuhan Persalinan dan Bayi Baru Lahir. Jakarta Trans Info Media,2013

Kementerian Kesehatan Republik Indonesia. Buku Saku Pelayanan Kesehatan Ibu di Fasilitas Kesehatan Dasar dan Rujukan. 2013.

Kementerian Kesehatan Republik Indonesia. Buku Saku Pelayanan Kesehatan Neonatal Esensial, 2010.

Kementerian Kesehatan Republik Indonesia. Profil Kesehatan Indonesia. Kesehatan keluarga, 2015.

Kementrian agama, RI. Al-Quran Dan Terjemahannya. CV Penerbit diponogoro . Bandung, 2011.

Lyndon 2014, Asuhan Neonatus Bayi dan Balita, Binarupa Aksara Publisher, Tangerang Selatan.

Marmi. Kukuh Rahardjo. Asuhan Neonatus Bayi, Balita, dan Anak Prasekolah, 2015.

Maryunani, A. Eka Puspita S. Asuhan kegawatdaruratan Maternal dan Neonatal, 2013.

Maryunani, Anik. Asuhan Bayi Dengan Berat Badan Lahir Rendah. Jakarta Timur: CV. Trans Info Media. 2013.

Nurlaila,Dkk. Jurnal. Hubungan Pelaksanaan Perawatan Metode Kangguru (PMK) dengan kejadian Hipotermia Pada Bayi Baru Lahir Rendah (BBLR): Poltekkes Kemenkes Kaltim, Vol III No 9, 2015. 
Saifuddin, Bari danWinkjosastro. 2014. Buku Panduan Praktis Pelayanan Kesehatan Maternal dan Neonatal, Tridasa Printer, Jakarta.

Saleha, Sitti .Asuhan Kebidanan Neonatus Bayi dan Balita, Alauddin University press, 2012.

Shihab, MQ. Tafsir Al Mishbah: Pesan. Kesan dan Keserasian Al-Quran, vol 1. Jakarta: Lentera Hati.2002.

- Tafsir Al Mishbah: Pesan. Kesandan Keserasian Al-Quran, vol 2. Jakarta: Lentera Hati.2002.

- Tafsir Al Mishbah: Pesan. Kesan dan Keserasian Al-Quran, vol 8. Jakarta: Lentera Hati.2002.

Trisnawati Frisca. Pengantar Ilmu Kebidanan. Prestasi Pustaka. Jakarta, 2016

Purwoastuti Endang, Thdan Elisabeth Siwi W. Asuhan kebidanan Kegawatdaruratan Maternal \& Neonatal. Pustaka baru press. Yogyakarta, 2015

Rahardjo, Kukuh dan Marmi. 2014. Asuhan Neonatus Bayi, Balita dan Anak Prasekolah. Pustaka Pelajar: Yogyakarta.

WibowoS.. Jurnal. Perbedaan Antara Pengaturan Suhu Ruang Operasi $24^{\circ}-26^{\circ} \mathrm{C}$ dan $20^{\circ} 22^{\circ} \mathrm{C}$ Terhadap Suhu Bayi Lahir Kurang Bulan: Universitas Sebelas Maret /Rumah Sakit DR. Moewardi, Surakarta,Vol.18, No 5,2017

Yeyeh, A,R. Lia, Y. Asuhan Neonatus Bayi dan Balita. Trans Info Media, 2012.

Yongki.et al. Asuhan pertumbuhan Kehamilan, Persalinan, Neonatus, Bayi dan Balita. Muha Medica, 2012. 